\title{
IMPORTED RABIES IN A QUARANTINE CENTRE IN THE UNITED KINGDOM
}

\author{
M Catchpole (mike.catchpole@hpa.org.uk) ${ }^{1}$, L Thomas ${ }^{1}$, D Morgan ${ }^{1}$, K Brown $^{1}$, D Turbitt ${ }^{1}$, H Kirkbride ${ }^{1}$ \\ 1. Health Protection Agency, United Kingdom
}

On the evening of 25 April 2008, the Health Protection Agency of the United Kingdom (UK) was informed that rabies had been confirmed through post-mortem examination of a dog that had died that same day in a quarantine centre in London. The dog, approximately 10 weeks old, had been imported from Sri Lanka, through Heathrow Airport in London, on 17 April by a charity that 'rescues' stray animals from that country and imports them into the UK. The public health response was undertaken through the coordinated activities of the authorities responsible for animal and human public health respectively.

Animal health investigations ascertained that the index dog had been imported on 17 April along with 4 other dogs, following capture in Sri Lanka on 12 April, and that following an overnight stay at the Animal Reception Centre in Heathrow, it had been transferred to a quarantine centre, were it had been kept in an isolation unit with 4 other dogs until the time of its death. The dog was reported to have first developed signs compatible with rabies on 23 April. The four dogs kept in isolation with the index dog were destroyed and post mortem tissues sent for examination for evidence of rabies; none had exhibited compatible signs at the time of death.

The immediate human health priority was to identify all individuals who may have had contact with the index dog during the period that it was potentially infectious, and to undertake individual risk assessment for each person and offer prophylaxis, using a specially developed risk assessment algorithm. All direct contact with the animal between its 'rescue' in Sri Lanka and its death was considered to pose a potential risk of exposure to rabies virus, in line with national policy that is based on infectiousness potentially extending for up to a maximum of 14 days before onset of signs in dogs or cats [1] .

A systematic approach to identifying potential human contacts, based on an analysis of each step in the dog's journey from Sri Lanka to the quarantine centre on London. The head of the importing charity was interviewed to ascertain who might have had contact during the capture in Sri Lanka and during the time between capture and departure from that country. This led to the identification of four British nationals who had been involved in the rescue mission, and a Sri Lankan veterinarian who had vaccinated the dog two days before departure. The dog was transported to the UK on a non-stop flight, during which there would have been no contact between the dog and flight crew. Interviews with ground staff at Heathrow Airport identified two groups of staff with potential contact, the ground crew unloading the dogs from the plane, and staff working at the Animal Reception Centre in the airport (where the dog was kept overnight, prior to transfer to a quarantine centre). All staff at the Quarantine Centre and any visitors during the period that the dog was there were also identified through interviews with the quarantine centre manager.

A total of 42 people were risk assessed to ascertain their degree of contact with the puppy, their previous rabies immunisation status and their need for rabies post exposure prophylaxis (rabies vaccine +/- Human Rabies Immunoglobulin (HRIG)).

A total of 12 persons were found to have had direct physical contact with the puppy (body fluid contact with skin or mucous membranes and/or bites) during the relevant time period: 11 resident in the UK, and one (the veterinarian) in Sri Lanka. Four of these people had had high-risk contact with the puppy, all within the quarantine kennels. Three of these people were bitten by the puppy in the latter stages of its illness, and one received faecal matter from the puppy into the eye. Of the 11 persons who had had direct contact with the puppy in the UK, five had previous complete vaccination against rabies, three had previous incomplete vaccination (primary course without adequate boosters) and three were unimmunised. All 11 received rabies post exposure prophylaxis, including vaccine and immunoglobulin (HRIG) where indicated. Information was passed on to the Sri Lankan authorities about the veterinarian who had had contact with the puppy in Sri Lanka.

\section{Comment}

This incident occurred shortly after two other rabies incidents associated with the importation of dogs into the European Union (EU) $[3,4]$. In those incidents, the imported dogs were not subject to statutory quarantine requirements, and in one incident this is known to have resulted in indigenous transmission between dogs within the EU. The incident in the UK described here, and the recent incidents that came to light in France and elsewhere, have highlighted the continued rabies threat associated with the importation of dogs, and emphasises the following key elements to the successful prevention and control of rabies:

- Effective quarantine measures, with minimal handling of animals and use of appropriate protective clothing during transfer and initial assessment, particularly if showing signs of ill health; 
- The importance of ensuring that staff who may have contact with rabid animals are fully immunised, and that they maintain immunity through regular booster doses;

- The value of coordinated animal and human health responses, with regular and rapid communication.

This text is adapted from a news item originally published in the Health Protection Report of the Health Protection Agency on 2 May 2008 [2].

\section{References}

1. Bloomfield SF, Aiello AE, Cookson B, O'Boyle C, Larson EL. The effectiveness of hand hygiene procedures including handwashing and alcohol-based hand sanitizers in reducing the risks of infections in home and community settings. Am J Infect Control. 2007;35(10) Suppl 1:S27-64.

2. Lo JY, Tsang TH, Leung YH, Yeung EY, Wu T, Lim WW. Respiratory infections during SARS outbreak, Hong Kong, 2003. Emerg Infect Dis. 2005;11(11):1738-41.

3. Bloomfield SF, Cookson B, Falkiner F, Griffith C, Cleary V. Methicillin resistant Staphylococcus aurnded, antibiotic and hygiene teaching resource for junior and senior school children. Available from: http://www.e-bug.eu/ebug.nsf/ Home?OpenPage

23. European Centre for Disease Prevention and Control. Influenza Communication Toolkit Guidelines. Available from: http://ecdc.europa.eu/Health topics/ Seasonal\%20Influenza/toolkit/pdf/ECDC\%20Influenza\%20Toolkit\%20-\%20 Guideline\%20for\%20U83.

27. Rook GAW, Brunet LR. Old friends for breakfast. Clin Exp Allergy. 2005;35(7):841-2

28. Bloomfield SF. Significance of biocide usage and antimicrobial resistance in domiciliary environments. J Appl Microbiol. 2002;92 Suppl:144S-57S.

This article was published on 8 May 2008.

Citation style for this article: Catchpole M, Thomas L, Morgan D, Brown K, Turbitt $D$, Kirkbride H. Imported rabies in a quarantine centre in the United Kingdom. Euro Surveill. 2008;13(19):pii=18868. Available online: http://www.eurosurveillance.org/ ViewArticle.aspx?ArticleId=18868 